\title{
APLIKASI AUGMENTED REALITY MOBILE GAME UCING SUMPUT BERBASIS GPS BASED TRACKING
}

\author{
Yulizar Rahman \\ Fakultas Teknik, Program Studi Informatika \\ Universitas Siliwangi \\ Email: 157006098@unsil.ac.id \\ Eka Wahyu Hidayat \\ Fakultas Teknik, Program Studi Informatika \\ Universitas Siliwangi \\ Email: ekawahyu@unsil.ac.id \\ Rahmi Nur Shofa \\ Fakultas Teknik, Program Studi Informatika \\ Universitas Siliwangi \\ Email: rahmi.shofa@unsil.ac.id
}

\begin{abstract}
ABSTRAK
Permainan tradisional mulai terkikis oleh perkembangan zaman, menyebabkan anak-anak hanya mengetahui permainan tradisional tapi tidak pernah memainkan permainan tradisional tersebut. Salah satu permainan tradisionan yang di Indonesia yang mulai terlupakan adalah Ucing Sumput dari Jawa Barat. Untuk melestarikan permainan tradisional perlu dilakukan berbagai upaya guna menjamin permainan tradisional tersebut tetap eksis dalam bentuk yang berbeda. Untuk itu perlu dilakukan transformasi permainan tradisional menjadi game digital. Penelitian ini bertujuan untuk menjelaskan proses transformasi dan transisi game tradisional ke bentuk digital dan rekayasa permainan tradisional Ucing Sumput yang dapat dimainkan pada platform android. Kombinasi model ATUMICS dan MDLC digunakan sebagai model pembangunan Game. Penelitian ini berhasil membangun model usulan dan membangun game digital augmented reality Ucing Sumput berbasis gps based tracking. Permainan ini menggunakan metode gps based tracking dimana objek 3D disimpan di titik latitude dan longitude sebagai objek yang akan dicari oleh pengguna. Berdasarkan hasil pengujian alpha, semua fungsionalitas game sudah berjalan dengan baik. Dari pengujian beta didapat nilai persentase sebesar $80 \%$ sebagai feedback dari pengguna dengan interpretasi game diterima oleh pengguna dan dapat dikembangkan lebih lanjut.
\end{abstract}

Kata kunci: ucing sumput; augmented reality; gps based tracking, android.

\section{ABSTRACT}

Traditional games are being eroded by the times, causing children to only know the traditional game but never play the traditional game. One of Indonesia's traditional games that is getting forgotten is Ucing Sumput from West Java. To preserve traditional games, various efforts need to be made to ensure that traditional games still exist in different forms. For this reason, it is necessary to transform traditional games into digital games. This study aims to explain the process of transformation and transition of traditional games to digital forms and traditional game engineering Ucing Sumput that can be played on the Android platform. The combination of the ATUMICS and MDLC models is used as a game development model. This research succeeded in building a proposed model and building a digital augmented reality game Ucing Sumput based on gps based tracking. This game uses a gps based tracking method where 3D objects are stored at latitude and longitude points as objects to be searched by users. Based on the results of alpha testing, all game functionality is running well. From the beta test obtained a percentage value of $80 \%$ as feedback from users with the interpretation of the game accepted by the user and can be further developed.

Keywords: ucing sumput; augmented reality; gps based tracking; android. 


\section{PENDAHULUAN}

Permainan tradisional adalah permaianan yang sejak dulu sudah ada dan turun-temurun dimainkan, biasanya dalam permainan tradisional memiliki unsur-unsur budaya yang turun menurun dari para leluhur. Permainan tradisional merupakan bagian dari budaya suatu daerah sehingga harus tetap dilestarikan, karena budaya merupakan ciri khas dari suatu daerah dan banyak memiliki sisi positif yang berpengaruh terhadap tumbuh kembangnya karakter seseorang. Seiring dengan berjalannya waktu teknologi berkembang dengan pesat khususnya perangkat telekomunikasi. Modernisasi telah membuat teknologi mengalami transformasi yang pesat dan masuk ke segala sendi kehidupan manusia[11]. Perkembangan teknologi bukan hanya sekedar untuk menelpon maupun sms saja tapi telah merambah kesegala bidang termasuk perkembangan hiburan seperti video, music dan game. Game adalah salah satu media teknologi yang populer di kalangan masyarakat baik dari anak kecil maupun orang dewasa sebagai media hiburan [7].

Sekarang ini permainan tradisional sudah mulai ditinggalkan oleh anak-anak bahkan tidak sedikit anakanak yang tidak tahu apa itu permainan tradisional[10]. Salah satu permainan tradisional Indonesia yang mulai terlupakan adalah Ucing Sumput dari Jawa Barat atau Petak Umpet yang konsep permainannya adalah mencari, minimal dimainkan 2 orang dan umumnya dimainkan diluar ruangan. Ucing Sumput adalah salah satu permainan tradisional yang ada di Jawa Barat dan salah satu permainan yang harus ada dan tidak boleh terkikis oleh permainan modern. Permainan Ucing Sumput dapat dijumpai juga di daerah-daerah lain tidak hanya Jawa Barat tetapi dengan nama yang berbeda-beda sesuai daerah itu berada, antara lain didaerah Padang dengan nama Cumancik dan didaerah Yogyakarta dengan nama Delikan.

Melihat dari hal tersebut maka perlu Transisi permainan tradisional kedalam konsep game digital. Perlu dilakukan redesain dari permainan tradisional kedalam game digital. Permasalahan yang akan diselesaikan dalam penelitian ini adalah bagaimana model redesain permainan tradisional kedalam konteks digital tanpa menghilangkan karakter dan masih memiliki nilai yang sama dari permainan aslinya tetapi masih relevan untuk dimainkan dengan kondisi saat ini. Metode yang digunakan dalam penelitian ini adalah dengan pendekatan Eksperimental dan untuk pembuatan game dengan kombinasi metode ATUMICS dan MDLC. Teknologi yang pas dalam peningkatan tersebut adalah Augmented Reality (AR), AR adalah konsep pelapisan konten visual seperti grafik di atas pemandangan dunia nyata seperti yang terlihat melalui sebuah kamera [1][4]. Perangkat lunak game dibuat menggunakan Unity EngineUnity merupakan salah satu perangkat lunak yang digunakan untuk pengembangan multi platform game yang didesain semudah mungkin untuk digunakan [2].

\section{METODOLOGI PENELITIAN}

Metodologi yang digunakan pada penelitian ini adalah kombinasi dari metode MDLC dan ATUMICS. Diagram alur penelitian dapat dilihat pada Gambar 1.

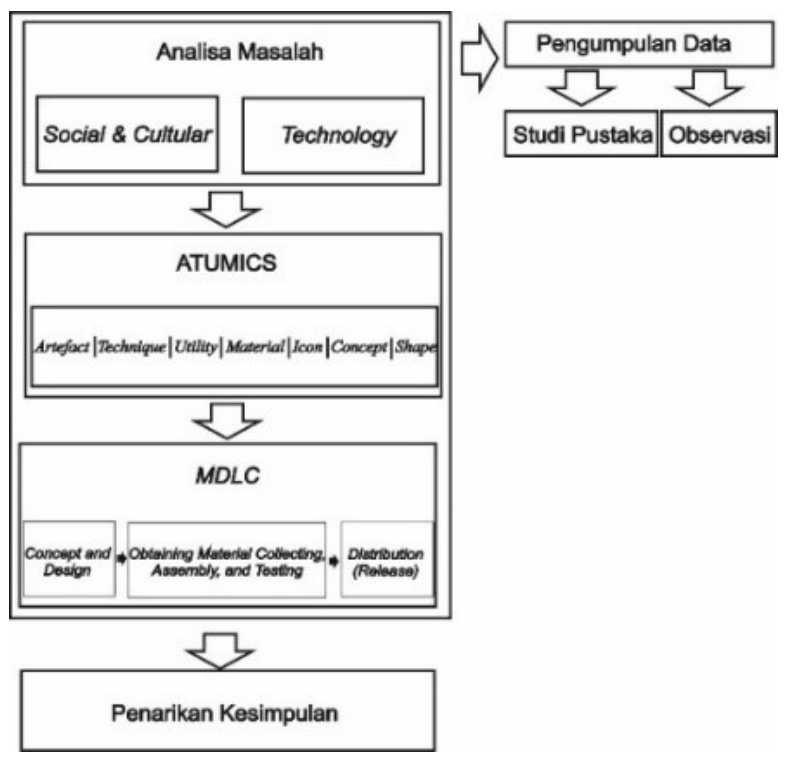

Gambar 1. Diagram Alur Penelitian

Dalam penjelasan yang terdapat pada gambar 1 ada beberapa analisa masalah dalam game. Pada proses Analisa masalah ini menggunakan dua faktor. Menjelaskan tentang aktivitas manusia dalam 
kehidupan sehari-hari seperti cara berpikir, cara bekerja dan bermain dipengaruhi oleh sosial dan budaya tempatnya berada. Permainan Ucing Sumput adalah contoh bahwa permainan hadir karena kondisi sosial dan budaya tempat permainan itu dimainkan. Pengaruh teknologi terhadap permainan tradisional adalah sebagai media untuk melestarikan budaya melalui game mengenai permainan tradisional, permaian kehilangan jati diri, tidak bisa dipungkiri bahwa untuk generasi saat ini permainan-permainan tradisional telah tergantikan oleh permainan modern yang dikemas dalam bentuk teknologi. Karena pengaruh gadget dan sering berdiam diri dirumah menyababkan generasi 'millenial' kebanyakan bersifat introvert dan kurang peduli dengan keadaan sekitar [3], Terbukanya ruang informasi yang luas, memberikan dampak kepada mereka dimana mereka hanya 'mengenali' permainan tradisional dari informasi yang ada di internet tapi tidak 'mengalami' permainan tradisional tersebut. Perkembangan teknologi informasi berbasisi multimedia membawa dampak pada berbagai bidang kehidupan, misalnya dalam bidang game digital. Untuk menjelaskan transformasi permainan tradisional ke bentuk modern dilakukan pendekatan ATUMICS yang selanjutnya peran perekayasa sangat diperlukan. Pendekatan $M D L C$ dapat digunakan untuk membantu proses rekayasa produk game berbasis multimedia. Proses yang di usulkan dalam pengembangan produk multimedia game sama dengan proses pada $M D L C$. ATUMICS akan dijelaskan pada gambar 2 .

\subsection{Transformasi Permainan Tradisional Ke Modern}

Kamus bahasa Indonesia mengartikan transformasi sebagai perubahan rupa (bentuk, sifat, fungsi, dan sebagainya) secara berangsur-angsur dari suatu bentuk ke bentuk lainnya dan memberi respon terhadap perubahan yang dipengaruh faktor internal dan eksternal. Transformasi dari permainan tradisional ke modern sebagai bentuk dari pelestarian budaya dapat dilakukan dengan metode ATUMICS yaitu akronim dari Artefact, Technique, Utility, Material, Icon, Concept, dan Shape [3].

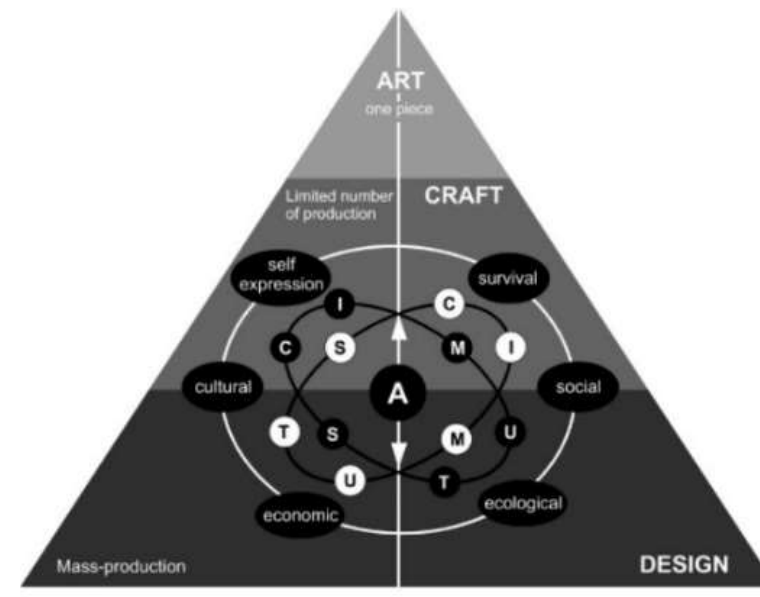

A: artefak, T: technique, U: utility, M: material, I: icon, C: concept, S: shape

Gambar 2. Bagan Metode ATUMICS [3][5].

Menurut metode ATUMICS, untuk perancangan sebuah produk budaya dapat dilihat dari dua level utama tingkat keberadaannya yaitu level mikro dan makro [3]. Perancangan sebuah produk harus menyatukan kedua level tersebut. Level mikro berhubungan dengan sifat teknis dan tampilan produk. Analisis dari suatu produk budaya dilakukan untuk mendapatkan elemen dasarnya yaitu Teknik/technique, kegunaan/utility, bahan/material, ikon/icon, konsep/concept, dan bentuk/shape. Level makro berhubungan dengan aspek yang lebih luas seperti motivasi dan ekspresi dari produk yang dihasilkan dan sebagai usaha menemukan keseimbangan yang tepat diantara aspek yang berbeda (budaya, social, ekologi, ekonomi, kelangsungan hidup) [3]. 


\section{HASIL DAN PEMBAHASAN}

\subsection{Transisi Permainan Tradisional Ke Modern}

Adaptasi permainan Ucing sumput kedalam permainan digital dengan metode ATUMICS bertujuan untuk memetakan elemen budaya tanpa meninggalkan esensi budaya dari permainan Ucing Sumput. Ucing Sumput dijelaskan dalam level mikro dan level makro, sebagai berikut:

1) Artefact

Artefact dari permainan Ucing Sumput dijelaskan sebagai berikut:

a) Maksud, Permainan Ucing Sumput biasanya dimainkan oleh anak-anak dan remaja. Ucing Sumput adalah sejenis permainan cari dan sembunyi.

b) Tujuan dari permainan ini adalah untuk mencari pemenang antara pemain yang sembunyi untuk mencari tempat bersembunyi dan tidak ketahuan oleh pemain yang mencari maupun yang jaga untuk mencari pemain yang bersembunyi.

2) Technique

Teknik bermain Ucing Sumput dapat dijelaskan sebagai berikut:

a) Teknik bermain permainan Ucing Sumput setidaknya memerlukan minimal 2 orang pemain, permainan Ucing Sumput atau petak umpet dimulai dengan biasanya berkumpul disuatu tempat , lalu untuk menentukan siapa yang jaga biasanya diundi dengan cara "suten" atau bias juga dengan cara "hompimpa" sesuai persetujuan pemain-pemainnya. Tujuannya untuk menentukan siapa yang menjadi Ucing atau pemain yang berperan sebagai pencari temantemannya yang bersembunyi. Si Ucing ini nantinya akan memejamkan mata atau berbalik sambil berhitung sampai waktu yang telah ditentukan, biasanya menghadap tembok, pohon atau apa saja supaya dia tidak melihat teman-temannya yang berlarian untuk bersembunyi[9]. Jika sampai waktu yang telah ditentukan selesai maka pemain yang kebagian jaga akan mulai mencari teman-temannya yang telah bersembunyi. Jika yang jaga telah menemukan temannya yang bersembunyi, maka yang jaga tadi akan berlari sambal kembali ke benteng untuk menepuk benteng sambil berkata "hong". Jika si Ucing atau yang jaga hanya menyebutkan namanya saja maka dianggap tidak sah dan permainan harus diulang dari awal. Selain itu, jika ada salah satu temannya ada yang bisa mendahului si ucing untuk menepuk atau menyentuh benteng dan berteriak "hong" maka seluruh anak yang sembunyi menang dan si ucing kalah[9]. Permainanpun harus diulang dengan yang kalah tadi sebagai yang jaga. Jika pemain yang bagian jaga dapat menemukan seluruh pemain yang bersembunyi maka dinyatakan sebagai pemenang tapi jika tidak bisa ditemukan dalam waktu yang telah ditentukan maka dinyatakan kalah.

b) Keahlian Persiapan yang diperlukan untuk bermain permainan Ucing Sumput khususnya untuk pemain yang kebagian untuk bersembunyi adalah untuk mencari tempat bersembunyi yang dapat tidak diketahui oleh pemain yang mencari tempat sembunyi terbaik yang dianggap tidak diketahui oleh penjaga disekitar area yang telah disepakati.

c) Peralatan permainan ini menggunakan peralatan tapi jika kondisi tempat bermain tidak ada dinding sebagai base nya maka diganti dengan genteng dan hong dilakukan dengan menginjak genteng tersebut.

3) Utility

Utility dari permainan Ucing Sumput dijelaskan sebagai berikut:

a) Fungsi Permainan Ucing Sumput dimainkan untuk mengisi waktu luang, mengajarkan kebersamaan dan mengasah kemampuan pemain untuk sembunyi dan mencari.

b) Kegunaan Permainan Ucing Sumput dapat dijadikan sebagai sarana hiburan, mengajarkan sportivitas dan belajar taat aturan.

c) Kebutuhan Permainan ini mudah dimainkan, dapat dimainkan ditempat terbuka dilahan yang luas diluar rumah semakin lahannya luas semakin banyak juga yang dapat ikut bermain ataupun ditempat yang tertutup didalam ruangan tetapi ada batasan pemain untuk didalam ruangan tergantung ukuran ruangannya semakin ruangannya sempit semakin sedikit juga yang dapat bermainnya.

4) Material

Tidak ada material yang dibutuhkan dalam permainan Ucing Sumput ini dan hanya membutuhkan tempat untuk bersembunyi bisa dilahan luas ataupun didalam ruangan. 
5) Icon

Permainan Ucing Sumput dapat di identifikasi dari kemampuan dan pengetahuan mencari pemain yang bersembunyi dan kemampuan pemain untuk bersembunyi agar tidak dapat ditemukan oleh pemain yang mencari. Permaian tradisional Ucing Sumput dinamai berdasarkan asalnya seperti di Jakarta disebut Petak Umpet, di Yogyakarta disebut Delikan dan di Jawa Barat sendiri disebut Ucing Sumput serta masih banyak lagi dari daerah lainnya.

6) Concept

Konsep dari permainan Ucing Sumput dapat dilihat dari sisi tampilan visualnya, bentuk, ikon, dan kegunaan saat permainan ini dimainkan. Permainan ini dimainkan diluar rumah serta hasil permainan menang dan kalah ditentukan berdasarkan hasil akhir yang dapat dilihat secara visual.

7) Shape

Unsur shape yang dapat dilihat dalam permainan ucing sumput ini adalah tempat bersembunyi yang biasanya digunakan pemain yang bersembunyi agar tidak dapat ditemukan oleh pemain yang jaga atau pemain yang mencari contohnya tong, pintu dan barang-barang yang dapat digunakan untuk tempat bersembunyi.

8) Motivasi

Motivasi dimaksudkan untuk menjelaskan level makro dari permainan Ucing Sumput. Tingkatan motivasi ini memiliki andil terhadap porsi permainan.

a) Motivasi Utama. Berupa motivasi budaya maka harus banyak mengenalkan pelestarian budaya. Motivasi ini agar 'millenial' tidak hanya mengetahui permainan tradisional tapi dapat mengenal permainan dan merasakan pengalaman memainkannya.

b) Motivasi Sekunder. Berupa motivasi sosial dan ekonomi. Motivasi sosial dari permainan ini dapat dijadikan sebagai sarana komunikasi antar pemain baik saat dimainkan secara tradisional ataupun secara digital.

c) Motivasi Lain. Berupa motivasi ekologi, kelangsungan hidup, dan kreasi ekspresi. Untuk pembangunan game digital motivasi ini dapat dijadikan acuan dalam pembuatan game Ucing Sumput digital.

Dengan pertimbangan ATUMICS diatas, maka dihasilkan transisi dari permainan tradisional kedalam digital dengan perbandingan transisi kondisi permainan sesungguhnya, kondisi permainan dalam bentuk digital atau kedalam game android, Android adalah sebuah sistem operasi mobile yang berbasiskan pada versi modifikasi dari linux [8]. Penyesuaian peraturan dari game yang akan dibangun dengan hasil sebagai berikut:

Tabel 1. Hasil transisi

\begin{tabular}{ll}
\hline Ucing Sumput & Game Digital \\
\hline $\begin{array}{l}\text { Jumlah pemain bisa sampai 15-20 } \\
\text { pemain }\end{array}$ & $\begin{array}{l}\text { Jumlah 1 pemain dan haru } \\
\text { mencari pemain yang } \\
\text { disembunyikan oleh sistem }\end{array}$ \\
$\begin{array}{l}\text { Pembagian tugas pemain dapat sebagai } \\
\text { pencari yang dicari }\end{array}$ & $\begin{array}{l}\text { Pengguna hanya sebagai } \\
\text { pencari }\end{array}$
\end{tabular}

Area permainan dapat bebas pemain Area permainan telah yang menentukan ditentukan oleh sistem dan hanya dapat dimainkan ditempat-tempat tertentu

Ketika pencari menemukan pemain Ketika menemukan pemain yang bersembunyi maka pencari yang bersembunyi klik tersebut menyebutkan nama lalu lari objeknya agar score nya kebase untuk mengatakan hong bertambah

Waktu permainan pagi sampai Lamanya permainan dibatasi dengan sore tidak dilakukan malam waktu yang diberikan oleh hari "pamali"
Penyesuain Peraturan

Pengguna hanya sebagai pencari dan yang bersembunyi telah disedikan oleh sistem

Karena pengguna hanya sebagai pencari, maka yang bersembunyi telah disedikan oleh system menggunakan titik koordinat latitude \& longitude Penempatan area bermain ditentukan oleh penyimpanan pemain yang bersembunyi menggunakan latitude \& longitude Ada jumlah score yang telah ditentukan apabila scorenya telah maksimal maka dianggap menang

Lamanya permaian perlu dibatasi Batasan waktu dengan level yang berbeda-beda 
Base berupa dinding atau tihang

Awal permainan ada undian seperti "suten" atau "hompimpa"
Base tidak berupa dinding atau Tidak perlu dipertimbangkan atau tihang bukan masalah utama Pengguna langsung sabagi pencari bukan sebagai yang dicari

\subsection{Pembangunan Game Ucing Sumput}

Metode perancangan pada penelitian ini menggunakan adalah Multimedia Development Life Cycle $(M D L C)$, metode ini terdiri dari Concept, Design, Material Collecting, Assembly, Testing, Distribution [6].

1) Concept

Pada tahap ini konsep aplikasi multimedia yang akan dikembangkan atau dibangun mulai dibentuk berdasarkan ide yang ada. Tahapan ini merupakan bagian perancangan bagaimana aplikasi itu akan berjalan pada sebuah system

Tabel 2. Deskripsi konsep game

\begin{tabular}{ll}
\hline Judul & $\begin{array}{l}\text { Augmented Reality Mobile Game Ucing Sumput } \\
\text { Berbasis GPS Based Tracking }\end{array}$ \\
\hline Audiens & Anak-anak \\
Durasi & Sampai dinyatakan kalah oleh sistem \\
Teks & Text untuk petunjuk permainan \\
Image & Gambar dan icon $(* . p n g)$ \\
Audio & Instrumen dengan format*.mp3 \\
Objek & Objek 3D (.FBX) \\
Interaktifitas & Tombol dan link \\
Tema & Permainan Mencari \\
Karakter objek & Terdiri dari 4 karakter \\
Deskripsi & Game ini menceritakan tentang permainan tradisional \\
& Ucing Sumput yang dibentuk kedalam digital agar \\
& lebih mudah untuk dimainkan. \\
\hline
\end{tabular}

2) Design

Tahapan yang menjelaskan mengenai storyboard, struktur navigasi, dan Perancangan sistem game menggunakan pendekatan Unified Modeling Language (UML). Struktur navigasi menggunakan pendekatan Hirarki dimana pengguna melakukan navigasi dari satu informasi atau menu ke informasi atau menu lainnya secara bertingkat disepanjang struktur menu yang terbentuk.

3) Obtaining Content Material

Tahapan ini menyiapkan material dan memproduksi elemen-elemen yang dibutuhkan, seperti pembuatan objek 3D, pembuatan antarmuka pengguna, dan pembuatan kode program. Untuk pembuatan objek 3D dan pembuatan animasi untuk loading screen menggunakan aplikasi Unity. User interface dibuat berdasarkan hasil rancangan pada tahap design dan dibuat menggunakan aplikasi pengolah gambar. Sedangkan pembuatan kode menggunakan bahasa pemrograman $C \#$, proses coding dilakukan pada visual studio 2017.

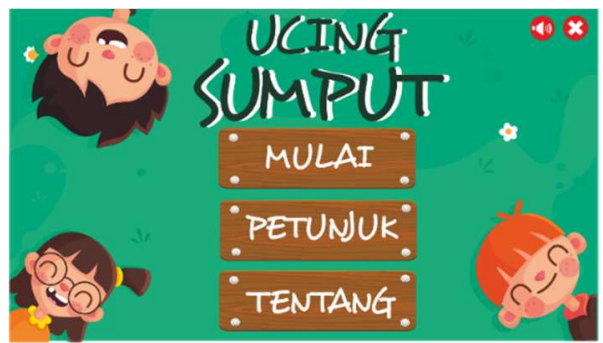

Gambar 3. Menu Utama 


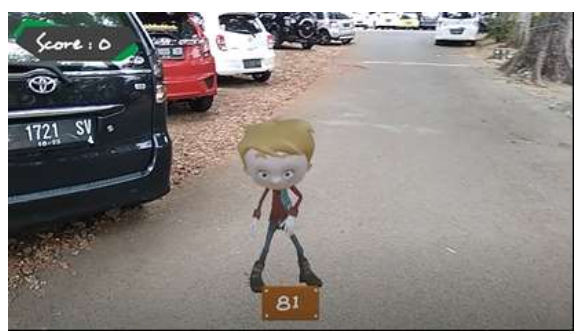

Gambar 4. Screen Gameplay AR

4) Assembly

Tahap ini melakukan penggabungan semua elemen multimedia yang telah dibuat pada tahap obtaining material collecting dan konsep gameplay sesuai skenario yang dibuat menjadi satu kesatuan. Penggabungan material pada lingkungan developer menggunakan program Unity.

5) Testing

Alpha Testing produk game dilakukan dengan pendekatan Black-Box dengan tujuan untuk menguji fungsionalitas sistem yang ada pada game yang dibuat agar sistem yang dibuat terhindar dari kegagalan dalam penggunaan. Pengujian dilakukan pada lingkungan yang terbatas pada sisi developer. Sedangkan Beta Testing dilakukan dengan tujuan untuk memvalidasi keguanaan, fungsi, kompabilitas, dan uji realibitas dari game. Pengujian tersebut dilakukan dengan teknik sampling insidental dengan 20 pertanyaan dalam kuisioner berbentuk skala likert. Hasil akhir pengujian dari uji fungsionalitas didapat bahwa semua dari kasus uji yang dilakukan semua fungsi dapat bekerja sesuai fungsinya. Sedangkan hasil kuisioner didapat nilai persentase sebesar $80 \%$ dan di interpretasikan bahwa game yang dibuat berada pada interpretasi "Sangat Sesuai" dan dapat didistribusikan.

6) Distribution

Tahapan ini merupakan tahapan terakhir dari rangkaian pengembangan game dengan pendekatan MDLC. Distribusi game dilakukan secara online, dimana game yang dibuat di unggah google drive yang mana link nya bisa dibagikan. Gambar 5 adalah tampilan hasil unggah Game Ucing Sumput.

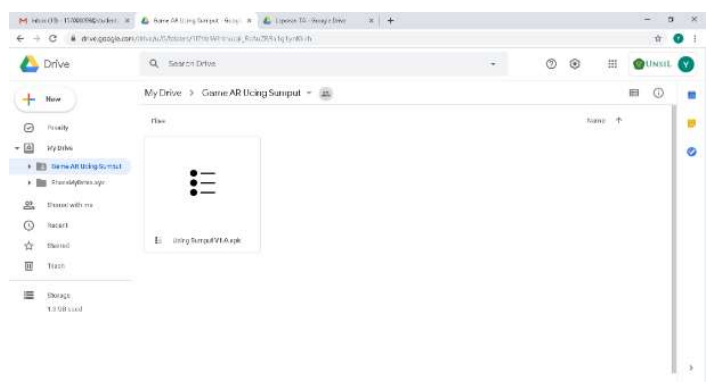

Gambar 5. Distribusi Game

\section{KESIMPULAN}

Berdasarkan hasil penelitian yang telah dilakukan, dapat disimpulkan sebagai berikut:

a. Telah dihasilkan produk game Ucing Sumput yang dapat memberikan pengalaman baru dengan menggunakan teknologi Augmented Reality dan berbeda bagi user dalam bermain permainan tradisioanl yang di ubah kedalam bentuk digital.

b. Telah dihasilkan produk game Ucing Sumput yang dapat berjalan pada perangkat smartphone Android yang dilengkapi dengan 4 Objek 3D yang menggunakan metode GPS Based Tracking atau disembunyikan dibeberapa titik latitude dan longitude yang telah ditentukan.

c. Telah dilakukan pengujian terhadap aplikasi menggunakan 4 aspek yaitu, aspek Antarmuka, aspek Fungsi, aspek Informasi dan aspek Teknis pada game Ucing Sumput. 


\section{DAFTAR PUSTAKA}

[1] Pragestu, S., Sujiani, H., \& Negara, A. B. P. (2015). Implementasi Augmented Reality dengan Memanfaatkan GPS Based Tracking pada Sistem. Jurnal Edukasi Dan Penelitian Informatika (JEPIN), 1(2), 122.

[2] Nugraha, I. S., Satoto, K. I., \& Martono, K. T. (2014). Pemanfaatan Augmented Reality untuk Pembelajaran Pengenalan Alat Musik Piano. Jurnal Teknologi Dan Sistem Komputer, 2(1), 62-70. https://doi.org/10.14710/JTSISKOM.2.1.2014.62-70

[3] Hidayat, E. W., Aldya, A. P., Tania, P., \& Miranti, A. (2019). Game Adu Muncang Berbasis Android. $1,13-20$.

[4] Prasetia, R., Hidayat, E. W., \& Shofa, R. N. (2018). Pengembangan Aplikasi Panduan Pengenalan Kampus Universitas Siliwangi Berbasis Augmented Reality Pada Perangkat Android. Jurnal Teknik Informatika Dan Sistem Informasi, 4(3), 478-487.

[5] Khamadi, K., \& Senoprabowo, A. (2017). Adaptasi Permainan Papan Tradisional ke dalam Permainan Digital dengan Pendekatan Atumics: Studi Kasus Permainan Mul-Mulan. Seminar Nasional Seni Dan Desain 2017, 2, 386-393. https:/www.neliti.com/id/publications/196106/adaptasi-permainan-papantradisional-ke-dalam-permainan-digital-dengan-pendekata

[6] Hidayat, E. W., Rachman, A. N., \& Azim, M. F. (2019). Penerapan Finite State Machine pada Battle Game Berbasis Augmented Reality. Jurnal Edukasi Dan Penelitian Informatika (JEPIN), 5(1), 54. https://doi.org/10.26418/jp.v5i1.29848

[7] Hormansyah, D. S., Ririd, A. R. T. H., \& Pribadi, D. T. (2018). Implementasi Fsm (Finite State Machine) Pada Game Perjuangan Pangeran Diponegoro. Jurnal Informatika Polinema, 4(4), 290. https://doi.org/10.33795/jip.v4i4.222

[8] Rio, U., Erlinda, S., \& Haryono, D. (2016). Implementasi Model Mobile Augmented Reality e-Booklet untuk Mempromosikan Object Wisata Unggulan Provinsi Riau dengan metode 3D Object Tracking. INOVTEK Polbeng - Seri Informatika, 1(2), 177. https://doi.org/10.35314/isi.vli2.137.

[9] Marnes. (2015). Permainan Ucing Sumput atau Petak Umpet. Www.Marneskliker.Com/. https://www.marneskliker.com/2015/01/permainan-ucing-sumput-atau-petakumpet.html? showComment $=1421767818528$

[10] Anggita, G. M. (2019). Eksistensi Permainan Tradisional sebagai Warisan Budaya Bangsa. JOSSAE : Journal of Sport Science and Education, 3(2), 55. https://doi.org/10.26740/jossae.v3n2.p55-59

[11] Mulyadi, M., Zulkarnain, I., \& Laugu, N. (2019). Adaptasi pustakawan dalam menghadapi kemajuan teknologi. Berkala Ilmu Perpustakaan Dan Informasi, 15(2), 163. https://doi.org/10.22146/bip.39843 